\title{
Autorenverzeichnis 1981
}

Ackermann, R. H., 9 Ahnefeld, F. W., 22, 158, 244 Altemeyer, K.-H., 36 Arnold, K., 234

Bäßler, K. H., 306 Balogh, D., 96 Barth, H., 69, 114 Behrendt, W., 104 Bethke, U., 35, 69, 114

Biebl, A., 224 Biedermann, H., 16, 206 Bindewald, H., 36 Bock, P. R., 147 Böhles, H., 77

Brandl, M., 234 Breucking, E., 36 Bünger, B., 184 Burger, U., 108

Classen, C, 104 Czaika, A., 181

Dick, W., 36, 190, 224 Dölp, R., 22, 244 Dudziak, R., 88

Egberts, E.-H., 266, 308

Ehrly, A. ML, 200

v. Eisenhart-Rothe, B., 172

Falk, K., 270 Fehm, H., 190 Flora, G., 206 Förster, H., 50, 88 Fuchs, H.-H.,234

Gahr, R., 147

Geiger, K., 35, 69, 114

Georgieff, M., 35,69, 114

Graf, H., 124

Grünert, A., 22, 61, 158, 244

Hackl, J. M., 96 Haux, P., 69, 114 Heesink, R., 4 Helbig, J., 302 Held, W.,266 Heller, W., 124

Hempel, V., 124 Hollmen, A., 214 Horbach, L., 218, 266, 308 Hruby, K., 44

Junger, K., 266

Kattermann, R., 69, 114 Kessler, G., 172 Kleinberger, G., 44, 56 Klose, R., 181,270 Knoche, E., 190, 224

Koerner, K., 253 Kubanek, B., 253 Knuiman, J. T., 4

Landgraf, H., 200 Lange, H., 291 Lochs, H., 56 Löhlein, D., 133 Lotz, P., 61, 158 Lürig, C, 28

Luft, D., 163 Lutz, H., 35, 69, 114

Malchow, H., 218, 266, 308 Monnens, L., 4 Müller, P. H., 266, 308

Nuutinen, L. S., 214

Pfaender, M., 141 Pihlajaniemi, R., 214 Podlesch, I., 291 Prestele, H., 266, 308

Raute, M., 69 Rippl, H.-J., 82 Ryhänen, P., 214

Saeger-Lorenz, K., 200 Seeling, W., 36

Semler, P., 82 Sporn, P., 56 Stampe, D., 253 Storz, L. W., 69 Strecker, J., 190

Schlürmann, D., 141 Schmitz, J. E., 61, 158,244 Schmülling, R., 266, 308 Schöch, G., 36

Schöntag, G., 172

Traub, E., 190 Trijbels, F., 4 Tyrväinen, L., 214

Unseld, H., 141

Vogel, C., 200 Voigt, E., 141

Weber, S., 308 Wicarkzyk, C., 88 Widhalm, K., 56 Wiedeck, H., 22 Wiener, H., 44

Zander, R., 274 Zick, R., 133 